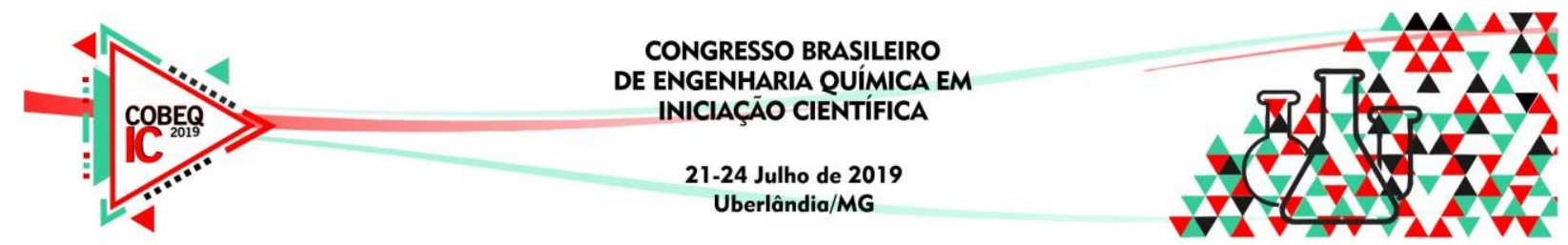

\title{
ESTUDO DO PONTO DE CARGA ZERO E ANÁLISE POR ESPECTROSCOPIA DE INFRAVERMELHO DO PÓ DA CASCA DE BANANA (Musa spp.) COM POTENCIAL BIOADSORVENTE DE COMPOSTOS CONTIDOS NA GASOLINA
}

\author{
G. C. F. DA SILVA ${ }^{1}$, G. A. S. GONÇALVES ${ }^{1}$, C. J. F. PASCHOAL ${ }^{1}$, S. L. S. \\ NASCIMENTO e C. S. S. PEREIRA ${ }^{1}$ \\ ${ }^{1}$ Universidade de Vassouras, Curso de Engenharia Química E-mail \\ para contato: gui.couto61@gmail.com
}

\begin{abstract}
RESUMO - Com a extensão do número de leis que visam um melhor controle ambiental sobre a maioria das atividades industriais, é possível destacar uma maior preocupação das indústrias e corporações com o tratamento de rejeitos líquidos e sólidos e a prática da logística reversa em seu cenário. Com o aumento dessa percepção é necessário à implementação de processos mais eficazes para o tratamento de efluentes contaminados. Uma prática que vem sendo muito estudada é a adsorção. O objetivo deste trabalho foi a caracterização da banana (Musa spp.) uma das frutas tropicais mais abundante do território brasileiro e que apresenta um tempo de prateleira curto, ocasionando a geração de resíduos da fruta. A caracterização foi realizada quanto ao ponto de carga zero e composição química utilizando a espectroscopia no infravermelho (IV). Após os estudos foi possível concluir que os valores encontrados, estão de acordo com os encontrados na literatura em trabalhos realizados anteriormente. Os resultados indicaram a faixa do ponto de carga zero entre 5 e 8 e uma similaridade de cerca de $57,22 \%$ do adsorvente com o celofane em sua composição. Além disso, obtiveram-se grupos em bandas na região de 3400 a $3200 \mathrm{~cm}^{-1}$ característicos do $\mathrm{OH}$. E também, estiramentos na faixa de 3000 a $2800 \mathrm{~cm}^{-1}$ caracterizando grupos $\mathrm{CH}-\mathrm{OH},-\mathrm{CH}$ e $-\mathrm{CH}_{2}$; todos estes presentes na estrutura da celulose.
\end{abstract}

\section{INTRODUÇÃO}

No Brasil, os postos de abastecimento e revenda de derivados do Petróleo contribuem na degradação da fauna e flora aquática. Segundo a Agência Nacional do Petróleo, Gás Natural e Biocombustíveis (ANP, 2019), a comercialização de gasolina C em 2017 apresentou um aumento de $2,6 \%$ em relação a 2016 , com o total de 44,150 bilhões de litros.

A contaminação de águas subterrâneas é uma situação derivada de derrames e acidentes durante o transporte, exploração do petróleo e seus derivados. Além disso, há a ocorrência de 


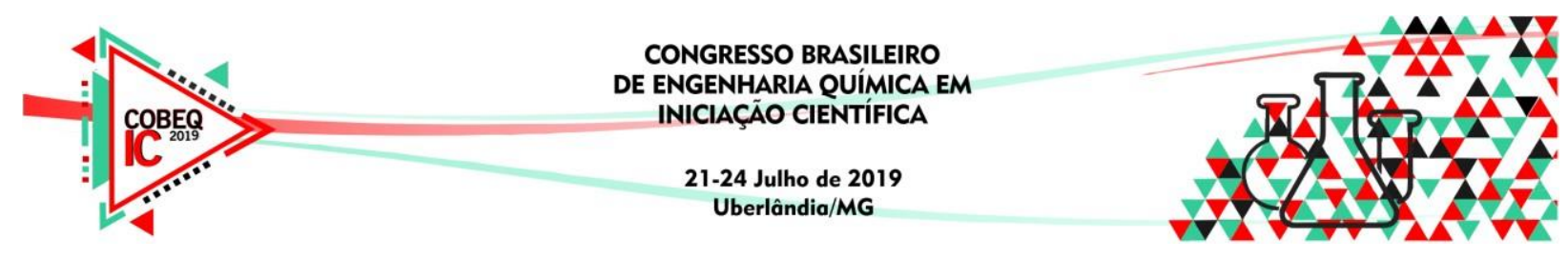

vazamentos oriundos dos tanques de armazenamento interno de gasolina, pois com o passar dos anos é possível que haja a corrosão (Corseuil e Marins, 1997).

De acordo com Abnadur (2005) existe a necessidade de remediação do constante lançamento de resíduos nos corpos hídricos, a fim da diminuição das degradações do ecossistema relacionados aos hidrocarbonetos presentes na gasolina. $\mathrm{O}$ processo de separação por adsorção - adesão das moléculas um fluido sobre uma superfície sólida - é uma metodologia já empregada pelas indústrias para controle de qualidade de efluentes.

Porém, de acordo com os trabalhos de Cionek (2013), os adsorventes envolvidos nesse procedimento apresentam alto custo, demandando um elevado investimento para a realização. Com intuito de buscar uma maneira de minimizar a despesa na produção, foram implementados os materiais bioadsorventes com custo mais acessível, tais como as biomassas

(Brandão et al., 2006) .

A banana se destaca como a segunda fruta em termos de importância na quantidade produzida, valor de produção e consumo na economia brasileira (SEBRAE, 2018). Recorrente ao consumo elevado tem-se a geração abundante de resíduos agroindustriais. Logo, é de suma importância uma prática que favoreça a diminuição de resíduos provenientes da fruta (Agrolink, 2015).

O processo de adsorção tem demonstrado ser um método eficaz no tratamento de efluentes com poluentes orgânicos de compostos presentes na gasolina. A utilização de cascas de frutas se tornou viável neste processo por possuírem um baixo custo e apresentarem potencial adsorvente para serem utilizados industrialmente (Moreira et al., 2000).

No processo bioadsorção, um dos principais estudos a ser realizado é a avaliação da variação do potencial hidrogeniônico na solução formada pelo adsorvato e o adsorvente, denominado ponto de carga zero (PCZ), procedimento que indica o ponto em que o $\mathrm{pH}$ da espécie é neutro.

Objetivando-se avaliar a potencialidade da bioadsorção da casca da banana, realizou-se o estudo para levantamento de dados do seu ponto de carga zero e análise de sua composição através da técnica de espectrometria.

\section{MATERIAIS E MÉTODOS}

A casca da banana passou por um processo de secagem em estufa por um período de 96 horas a $60^{\circ} \mathrm{C}$. Após trituração e peneiramento considerou-se para os ensaios o pó com granulometria de $1 \mathrm{~mm}$. O material obtido foi armazenado em dessecador para posterior ensaio.

A metodologia utilizada para a determinação do ponto de carga zero é denominada como o experimento dos 11 pontos. O ponto de carga zero foi determinado pesando-se cerca de 50 mg de pó da casca banana em $50 \mathrm{~mL}$ de água. Posteriormente, o $\mathrm{pH}$ das espécies foi ajustado com o auxílio de uma solução de $\mathrm{HCl} 0,1 \mathrm{Me} \mathrm{NaOH} 0,1 \mathrm{M}$, variando entre 2 até 12 . As amostras 


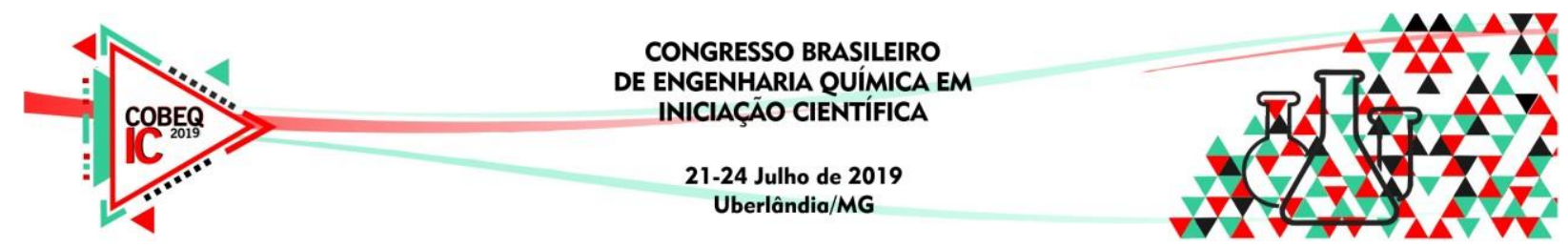

foram postas em agitação contínua a $100 \mathrm{rpm}$ por 30 minutos e em seguida mantidas em repouso por aproximadamente 24 horas para o ajuste do $\mathrm{pH}$ da solução, em temperatura ambiente. A Figura 1 apresenta as partículas da casca de banana imersas em água para o início dos testes.

Figura 1 - Solução formada por $50 \mathrm{mg}$ da casca de banana em $50 \mathrm{~mL}$ de água.

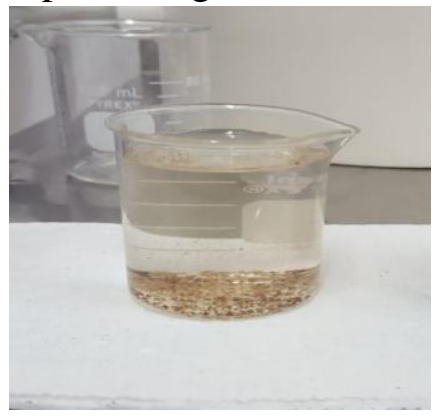

Além do estudo do ponto de carga zero, avaliou-se a composição da casca de banana através da análise de espectroscopia utilizando o equipamento Thermo Scientific Nicolet IZ10 Help FT-IR. A verificação no infravermelho pode ser definida como uma técnica química que identifica estruturas moleculares de uma amostra qualquer, o espectro de uma amostra fornece informações relevantes de como a molécula em estudo interage com a radiação do infravermelho, como existe um espectro único para cada tipo de molécula, pode-se distinguir diferentes composições e propriedades de um analito.

\section{RESULTADOS E DISCUSSÕES}

Com a realização das práticas em questão, foi possível adquirir informações importantes sobre a natureza da casca de banana como adsorvente. Os valores de $\mathrm{pH}$ após a aplicação do método podem ser visualizados a partir da tabela 1 em que se evidencia também a proximidade dos valores medidos após o repouso da solução.

Tabela 1 -Valores de $\mathrm{pH}$ iniciais e finais medidos a partir do cálculo de média aritmética antes e após o repouso por 24 horas da solução.

\begin{tabular}{|c|c|c|c|c|c|c|c|c|c|c|c|c|}
\hline Concentração & \multicolumn{10}{|c|}{ Resultados } \\
\hline \multirow{2}{*}{$\mathbf{5 0} \mathbf{~ m g} / \mathbf{5 0} \mathbf{~ m L}$} & $\begin{array}{c}\mathrm{pH} \\
\text { inicial }\end{array}$ & 2 & 3 & 4 & 5 & 6 & 7 & 8 & 9 & 10 & 11 & 12 \\
\cline { 2 - 13 } & $\begin{array}{c}\mathrm{pH} \\
\text { final }\end{array}$ & 2,04 & 3,75 & 5,70 & 6,26 & 6,48 & 6,49 & 6,62 & 6,56 & 7,39 & 7,06 & 9,20 \\
\hline
\end{tabular}

O ponto de carga zero da amostra avaliada destacado na Tabela 1 aproximou-se dos valores obtidos nos estudos de Silva (2014) em que os autores avaliaram a utilização da casca de banana como biossorvente para a adsorção de chumbo (II) em solução aquosa. O pH obtido 


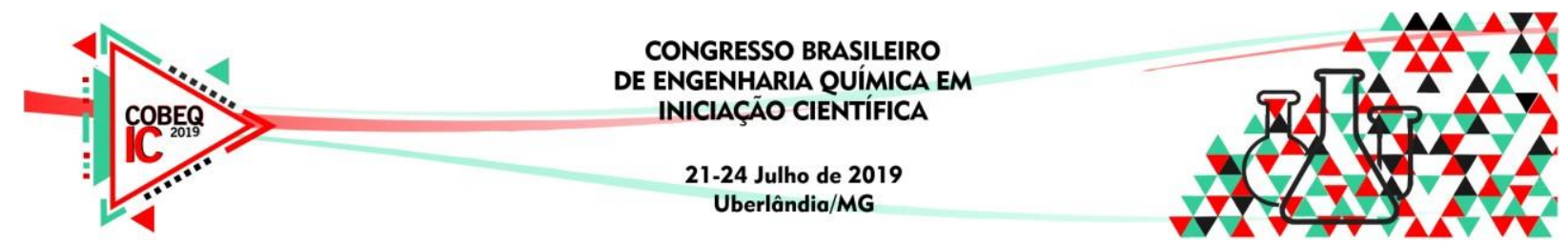

pelo autor foi 5,93 e 6,23. O mesmo comportamento foi observado por Paniagua et al. (2015) com resultados de $\mathrm{pH}$ entre 5 e 8 . No trabalho reportado por Silva (2014) o autor ressalta que fatores como umidade relativa do ar e teor de matéria orgânica podem influenciar no valor do PCZ. A diferença entre os valores pode ser devido aos diferentes tipos de tratamento das amostras.

É importante destacar que abaixo do PCZ da substância, sua superfície encontra-se carregada positivamente, formando atração com cargas negativas de um adsorbato. Já acima desse ponto ocorrerá atração eletrostática do adsorvente (carregado negativamente) com estruturas com caráter positivo na solução.

Com relação à caracterização qualitativa da composição do pó da casca da banana, os resultados da após análise de espectroscopia de infravermelho, apresentaram similaridade de $57,22 \%$ com o composto celofane presente na biblioteca do equipamento. A Figura 2 ilustra o espectro obtido.

Figura 2 - Espectro no infravermelho do pó da casca da banana

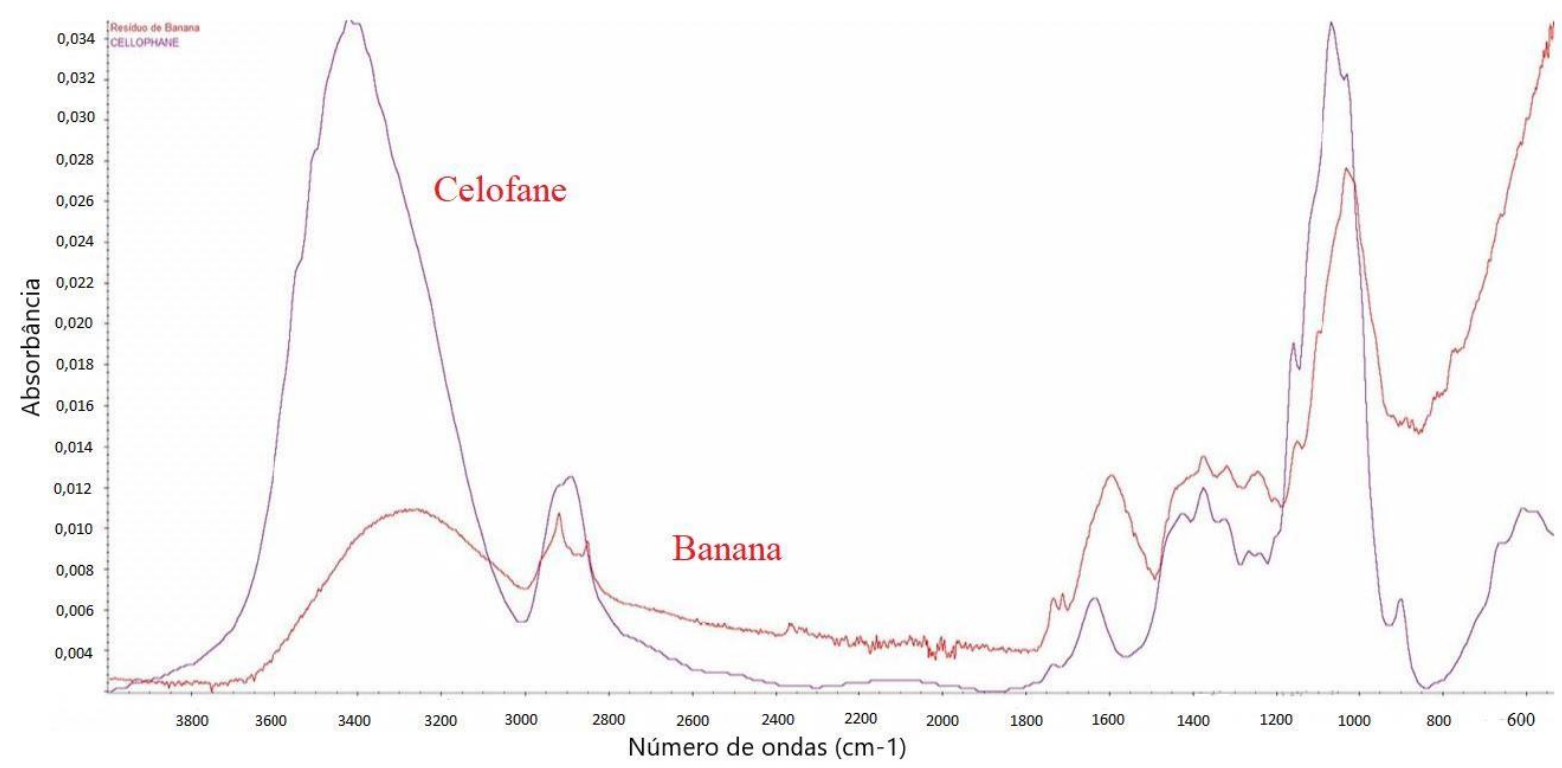

As bandas na região de 3400 a $3200 \mathrm{~cm}^{-1}$ podem ser relacionadas ao estiramento vibracional axial dos grupos $\mathrm{OH}$ característicos da celulose. $\mathrm{E}$ os grupos funcionais encontrados próximos aos espectros das bandas na região de 3000 a $2800 \mathrm{~cm}^{-1}$ estão atribuídos aos grupos $\mathrm{CH}-\mathrm{OH},-\mathrm{CH}$ e $-\mathrm{CH}_{2}$ de grupos alifáticos também encontrados na celulose de acordo com Cruz (2009) e Gouveia (1999).

A esta semelhança com o produto derivado da celulose, pode atribuir ao material uma propriedade considerada um indicador de um potencial adsorvente, pois estudos comprovam que cascas de frutas compostas por celulose, hemicelulose e lignina são substâncias indicadas 


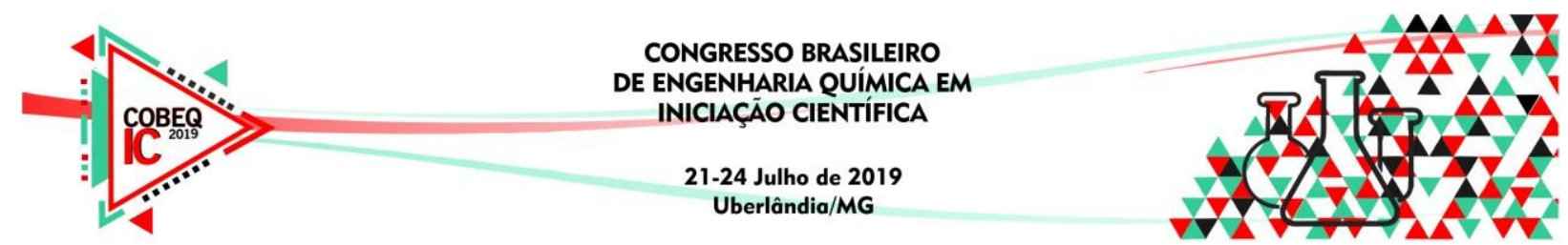

como influenciadoras na adsorção por possuírem grupos importantes como carbonilas, carboxilas, amina e hidroxilas, capazes de adsorverem os metais e outros componentes de um efluente contaminado (Silva, 2014).

\section{CONCLUSÃO}

A adsorção é um processo eficiente, mas para processamento desta técnica é necessário o conhecimento do material adsorvente. Destacando-se o ponto de carga zero, por permitir prever o pH ótimo do adsorvente utilizado. O conhecimento do PCZ da casca da banana foi de extrema valia para melhor adsorção dos compostos presentes na gasolina. Pois nele, a superfície possui densidade de carga igual a zero.

Assim, o pH da solução afetará diretamente as cargas da superfície, um pH alto favorece a adsorção de compostos orgânicos positivos, e potenciais hidrogênionicos abaixo do PCZ apresentam uma elevação da afinidade da farinha da banana com ânions da solução. A massa do bioadsorvente utilizado também pode ser considerada influenciadora na adsorção, pois com o valor da concentração da casca definido, consequentemente, haverá uma melhor precisão do número de sítios ativos. Assim, elevando a interação eletrostática com os adsorbatos suspensos na solução estudada.

Contudo, pode-se afirmar que é necessária a continuação dos estudos sobre o tema com ênfase na natureza do bioadsorvente apresentado, ressaltando a importância da redução dos rejeitos industriais, principalmente a contaminação dos derivados do petróleo.

\section{REFERÊNCIAS}

ABNADUR, A. Remediação de solo e água subterrânea contaminados por hidrocarbonetos de petróleo: estudo de caso na refinaria Duque de Caxias/RJ. Tese de mestrado, Curitiba: Universidade Federal do Paraná, 2005. AGROLINK. Banana é a fruta mais consumida pelos brasileiros, 2015. Disponível em: <https:/www.agrolink.com.br/noticias/banana-e-a-frutamais-consumida-pelos- brasileiros_223476.html>. Acesso em: 01 mar. 2019.

ANP. Agência Nacional do Petróleo, Gás natural e Biocombustíveis. Disponível em: <http://www.anp.gov.br/>. Acesso em: 05 mar. 2019.

BRANDÃO, P. C. Avaliação do Uso do bagaço de cana como adsorvente para remoção de contaminantes derivados do petróleo, de efluentes. Uberlândia: Faculdade de Engenharia Química da UFU, 2006. 147 p. (Dissertação, Mestrado em Engenharia Química).

CIONEK, C. A. Avaliação de carvões ativados de diferentes naturezas para adsorção de corante têxtil. 2013. 96 f. Dissertação de (Mestrado em Engenharia Química) - Universidade Estadual de Maringá, 2013. 


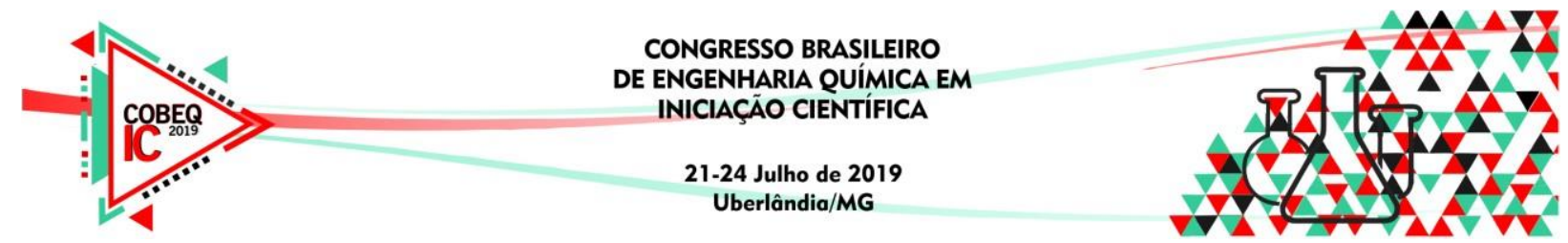

CORSEUIL, H. X.; MARINS, M. D. M. Contaminação de águas subterrâneas por derramamentos de gasolina: o problema é grave. Revista Engenharia Sanitária e Ambiental, v. 2, n. 2, p. 50-54, 1997.

CRUZ, Maria A R. da.; Utilização da casca de banana como biossorvente. 2009. 74 f. Dissertação - Universidade Estadual de Londrina, Londrina, 2009.

GOUVEIA, J.P.G. et al. Estudos das isotermas de sorção e calor isotérico do gengibre sem casca. In: CONGRESSO BRASILEIRO DE ENGENHARIA AGRÍCOLA, 28, Pelotas, Rio Grande do Sul. Anais... 1999. CD ROM 4P. 1999.

MOREIRA, R. F. P.; HUMBERTO, J. J., SOARES, J. L., 2000. Isotermas de Adsorção de Corantes sobre Carvão Ativado. II Encontro Brasileiro de Adsorção - II EBA, Florianópolis - SC, 85-91.

PANIAGUA, C. E. D. S. O uso da farinha da casca de banana in natura e quimicamente modificada com tiosemicarbazida na adsorção de arsênio, antimônio e selênio, 2015. Disponível em: <http://repositorio.ufu.br/handle/123456789/17437>. Acesso em: 02 mar. 2019.

SEBRAE. Serviço Brasileiro de Apoio às Micro e Pequenas Empresas. Disponível em: <http:// www.bibliotecas.sebrae.com.br/>. Acesso em: 09 abril.2019

SILVA, Nayara Cristina Romano. Utilização da casca de banana como biossorvente para a adsorção de chumbo (II) em solução aquosa. 2014. Trabalho de Conclusão de Curso. Universidade Tecnológica Federal do Paraná. 